\title{
Novel ceruloplasmin gene mutation causing aceruloplasminemia with diabetes in a Chinese woman: a case report
}

\author{
Yuanyuan Xiao, Chaoyu Zhu, Fusong Jiang, Qingge Gao, Huijuan Lu, Chen Wang, Li Wei \\ Shanghai Key Laboratory of Diabetes, Department of Endocrinology and Metabolism, Shanghai Jiao Tong University Affiliated Sixth People's \\ Hospital, Shanghai, China \\ Correspondence to: Li Wei. Shanghai Key Laboratory of Diabetes, Department of Endocrinology and Metabolism, Shanghai Jiao Tong University \\ Affiliated Sixth People's Hospital, 600 Yishan Road, Shanghai 200233, China. Email: 18930173636@189.cn.
}

\begin{abstract}
Hereditary aceruloplasminemia (ACP) is a rare adult-onset autosomal recessive disease characterized by a ceruloplasmin $(C P)$ gene mutation and defective or absent CP function. In the present study, we report a case of ACP in a 34-year-old Chinese woman with diabetes, fatigue, anxiety, and progressive membrane loss with low hemoglobin associated with microcytosis. The fasting glucose level was 5.6-7.96 mmol/L. Postprandial blood glucose ranged from 6.8 to $9.6 \mathrm{mmol} / \mathrm{L}$. The Stumvoll first-phase and second-phase insulin secretion disposition indices were very low, and the serum iron content was low, even though transferrin levels were normal. Moreover, the transferrin saturation was low (5\%), and the ferritin level was extremely high, above 2,000 $\mu \mathrm{g} / \mathrm{L}$ in the patient. Furthermore, her serum CP level was extremely low $(<0.0183 \mathrm{~g} / \mathrm{L})$. Abdominal computed tomography (CT) examination showed moderate iron overload in the liver. Brain CT also showed a mildly increased density of the bilateral thalami and basal ganglia. Finally, gene analysis showed a rare homozygous mutation $(c .146+1 \mathrm{G}>\mathrm{A})$ in the $C P$ gene and was diagnosed with ACP. To date, less than 60 family cases of ACP have been reported worldwide, and only two cases of ACP have been reported in China. Here, we report a case of ACP accompanied by diabetes with a novel mutation of the $C P$ gene, which suggests that increased awareness should be highlighted in this disorder as diabetes is an important typical symptom.
\end{abstract}

Keywords: Aceruloplasminemia (ACP); ceruloplasmin (CP); diabetes; case report

Submitted Apr 30, 2021. Accepted for publication Aug 12, 2021.

doi: 10.21037/apm-21-1086

View this article at: https://dx.doi.org/10.21037/apm-21-1086

\section{Introduction}

Hereditary aceruloplasminemia (ACP) (OMIM\#604290, ORPHA48818) is a rare adult-onset autosomal recessive disease characterized by a ceruloplasmin $(C P)$ gene mutation and defective or absent CP function. Human $\mathrm{CP}$ is encoded in 20 exons encompassing approximately $65 \mathrm{~kb}$ of DNA localized on chromosome 3q23-q24 (1). It is a copper-containing ferroxidase that is involved in maintaining iron homeostasis (2). Mutations in CP result in a strong reduction or absence of $\mathrm{CP}$, a ferroxidase activity, and subsequently lead to an accumulation of iron in organs, causing retinopathy, liver disease, anemia, and progressive neurological degeneration presenting with movement disorders (e.g., motor delay, dystonia, spasticity, and parkinsonism), cognitive dysfunction, ataxia, and diabetes mellitus (DM) (3). It was estimated that the incidence of APC was 1 per 2,000,000 in non-consanguineous marriages (4), which was first described in 1987 by Miyajima (5). Although ACP has also been described in other areas (6-8), most of the published cases originated in Japan. However, detailed case reports are limited, especially in China. Most importantly, DM could result from ACP due to the accumulation of iron in the pancreas. However, there is limited awareness regarding the association between $\mathrm{DM}$ and $\mathrm{ACP}$, since hyperglycemia was an uncommon clinical manifestation of ACP. Additionally, it was difficult to identify and diagnose a diabetes patient suffering from 
ACP.

In this report, we describe a Chinese patient with ACP who suffered from diabetes for more than 5 years before we recognized she had a homozygous mutation of the $C P$ gene inherited from her parents, and this mutation site has not been reported in China before. We present the following article in accordance with the CARE reporting checklist (available at https://apm.amegroups.com/article/ view/10.21037/apm-21-1086/rc).

\section{Case presentation}

All procedures performed in this study were in accordance with the ethical standards of the institutional and/or national research committee(s) and with the Helsinki Declaration (as revised in 2013). Written informed consent was obtained from the patient for publication of this case report and accompanying images. A copy of the written consent is available for review by the editorial office of this journal.

A 34-year-old woman was admitted to our clinic with a history of diabetes for more than 5 years. She was hospitalized with complaints of fasting hyperglycemia despite receiving multiple oral antidiabetic agents, with fasting blood glucose levels ranging between 8.4 and $12 \mathrm{mmol} / \mathrm{L}$ during the last 2 years, even though the postprandial blood glucose level was well controlled. In addition, the patient also suffered from fatigue, anxiety, and progressive remembrance loss.

Physical examination revealed no obvious abnormalities except for a lean body. Her BMI was $20 \mathrm{~kg} / \mathrm{m}^{2}$. Table 1 presents the primary laboratory findings. Her complete blood count showed that she had a low hemoglobin of $10.5 \mathrm{~g} / \mathrm{dL}$ (normal $13.0-17.5 \mathrm{~g} / \mathrm{dL}$ ) associated with microcytosis. The daily glucose monitoring (8 times) revealed that the postprandial blood glucose range from 6.8 to $9.6 \mathrm{mmol} / \mathrm{L}$; however, the fasting blood glucose was always greater than $7.8 \mathrm{mmol} / \mathrm{L}$. Homeostatic Model Assessment of Insulin Resistance (HOMA-IR) was elevated, whereas the quantitative insulin sensitivity check index (QUICKI) was decreased. Although insulin and $\mathrm{C}$-peptide levels were within the normal range, the Stumvoll first-and second-phase insulin secretion disposition indices were very low, indicating low beta cell function in the patient (Table 1). Furthermore, her anti-glutamic acid decarboxylase antibody and anti-IA2 antibody were negative, which ruled out the possibility of T1DM.
Chest computed tomography (CT), urinary ultrasound, and cardiac ultrasound findings were within normal limits. Ophthalmological examination (including fundoscopy and visual field tests) did not reveal retinal degeneration. However, abdominal ultrasound showed splenomegaly and intrahepatic hyperechogenicity, indicating metal deposits in the liver. To further explore, the abdominal CT examination of the liver was performed, and a moderate iron overload in the liver was determined and quantified as average of 95 HU (Figure 1A). Furthermore, CT also showed a mildly increased density of the bilateral thalami and basal ganglia (Figure 1B). All of this evidence indicated iron overload in the body.

To confirm this, we detected some relative indexes of iron metabolism, such as serum iron, total iron binding capacity, transferrin saturation, ferritin, and serum CP. As shown in Table 2, the serum iron content was low, even though transferrin levels were normal. Moreover, transferrin saturation was low (5\%), and ferritin level was extremely high above $2,000 \mu \mathrm{g} / \mathrm{L}$ in the patient. It is noteworthy that her serum CP levels was extremely low $(<0.0183 \mathrm{~g} / \mathrm{L} ; 0.2$ to $0.6 \mathrm{~g} / \mathrm{L})$. Therefore, $C P$ gene analysis of the patient and her parents was performed. A homozygous $C P$ gene mutation inherited from his father and mother (Figure 2) c.146+1G>A was identified. Her consanguineous parents carried the same heterozygous mutation in the $C P$ gene, which could be attributed to the ACP. Segregation analysis is shown in Figure 3.

In the area of treatment, iron chelation therapy is the mainstay for ACP. Considering the poor economic situation of this patient, we suggested accepting intravenous infusions of $500 \mathrm{mg}$ of desferrioxamine twice a week for 610 months and serum ferritin (SF) levels were measured every 2 months. After 6 months, her SF levels decreased and were maintained at $500-1,000 \mathrm{ng} / \mathrm{mL}$. Furthermore, to further control the blood glucose levels, we administer red neutral protamine Hagedorn (NPH) insulin, which may improve fasting hyperglycemia. During the follow-up period, her fasting blood glucose level was no more than $8 \mathrm{mmol} / \mathrm{L}$. Unfortunately, she was lost to follow-up after 6 months. Therefore, we had no information about the treatment outcome.

\section{Discussion}

In the present study, we reported a case of ACP in a 34-year-old Chinese woman with diabetes, fatigue, anxiety, and progressive remembrance loss with a homozygous 
Table 1 Laboratory assessments results of the patient

\begin{tabular}{|c|c|c|}
\hline Parameter & Value & Normal value \\
\hline WBC $\left(\times 10^{9} / L\right)$ & 3.6 & $3.5-9.5$ \\
\hline $\operatorname{RBC}\left(\times 10^{12} / \mathrm{L}\right)$ & 4.52 & $4.3-5.8$ \\
\hline $\mathrm{Hb}(\mathrm{g} / \mathrm{L})$ & 105 & $130-175$ \\
\hline $\mathrm{Ht}(\%)$ & 36.3 & $40-50$ \\
\hline MCV (fL) & 80.3 & $82-100$ \\
\hline $\mathrm{MCH}(\mathrm{pg})$ & 23.2 & $27-34$ \\
\hline $\mathrm{MCHC}(\mathrm{g} / \mathrm{L})$ & 289 & $316-354$ \\
\hline PIt $\left(\times 10^{9} / L\right)$ & 148 & $125-350$ \\
\hline Albumin (g/L) & 49 & $35-55$ \\
\hline ALT (U/L) & 61 & $0-65$ \\
\hline AST (U/L) & 40 & $8-37$ \\
\hline ALP (U/L) & 84 & $15-112$ \\
\hline$\gamma$-GTP (U/L) & 28 & $0-50$ \\
\hline BUN (mmol/L) & 4.6 & $2.5-6.4$ \\
\hline T-Bil $(\mu \mathrm{mol} / \mathrm{L})$ & 3.0 & $0.0-6.0$ \\
\hline $\mathrm{Cr}(\mu \mathrm{mol} / \mathrm{L})$ & 45 & $53-115$ \\
\hline $\mathrm{UA}(\mu \mathrm{mol} / \mathrm{L})$ & 310 & $210-430$ \\
\hline $\mathrm{Na}(\mathrm{mmol} / \mathrm{L})$ & 144 & $135-145$ \\
\hline $\mathrm{K}(\mathrm{mmol} / \mathrm{L})$ & 4.3 & $3.5-5.5$ \\
\hline $\mathrm{Cl}(\mathrm{mmol} / \mathrm{L})$ & 101 & $95-105$ \\
\hline FPG (mmol/L) & 8.28 & $3.9-5.8$ \\
\hline 2hPG (mmol/L) & 8.94 & $3.9-7.8$ \\
\hline $\mathrm{HbA1C}(\%)$ & 5.3 & $4.3-6.5$ \\
\hline GA (\%) & 15.6 & $11.0-17.0$ \\
\hline $\mathrm{TC}(\mathrm{mmol} / \mathrm{L})$ & 5.5 & $2.8-5.9$ \\
\hline $\mathrm{TG}(\mathrm{mmol} / \mathrm{L})$ & 1.36 & $0.45-1.81$ \\
\hline FINS $(\mu \mathrm{U} / \mathrm{mL})$ & 10.7 & $1.25-10.50$ \\
\hline FC-peptide & 1.49 & $0.82-2.5$ \\
\hline 2hINS ( $\mu \mathrm{U} / \mathrm{mL})$ & 24.71 & - \\
\hline 2hC-peptide & 4.14 & - \\
\hline \multicolumn{3}{|l|}{$\beta$ cell function } \\
\hline HOMA- $\beta$ & 44.8 & - \\
\hline 1st-phase secretion & -768.57 & - \\
\hline 2nd-phase secretion & 17.71 & - \\
\hline
\end{tabular}

Table 1 (continued)
Table 1 (continued)

\begin{tabular}{lcc}
\hline Parameter & Value & Normal value \\
\hline Insulin resistance & & \\
HOMA-IR & 3.93 & - \\
QUICKI & 0.62 & - \\
\hline
\end{tabular}

WBC, white blood cell; RBC, red blood cell; Hb, hemoglobin; $\mathrm{Ht}$, hematocrit; MCV, mean corpuscular volume; $\mathrm{MCH}$, mean corpuscular hemoglobin; $\mathrm{MCHC}$, mean corpuscular hemoglobin concentration; PIt, platelet; AST, aspartate transaminase; ALT, alanine transaminase; ALP, alkaline phosphatase; $\gamma$-GTP, $\gamma$-glutamyltranspeptidase; BUN, blood urea nitrogen; T-Bil, total bilirubin; $\mathrm{Cr}$, creatinine; $\mathrm{Na}$, serum sodium; $\mathrm{K}$, serum potassium; $\mathrm{Cl}$, serum chloride; FPG, fasting plasma glucose; $2 \mathrm{hPG}, 2$ hours postprandial blood glucose; HbA1c, hemoglobin A1c; GA, glycated albumin; TC, total cholesterol; TG, triglycerides; FINS, fasting insulin; FC-peptide, fasting C-peptide; 2hINS , 2 hours postprandial insulin; $2 \mathrm{~h} \mathrm{C}$-peptide, 2 hours postprandial C-peptide; HOMA- $\beta$, Homeostatic Model Assessment of $\beta$-cell function; HOMA-IR, Homeostatic Model Assessment of Insulin Resistance; QUICKI; quantitative insulin sensitivity check index.

mutation $(\mathrm{c} .146+1 \mathrm{G}>\mathrm{A})$ in the $C P$ gene, and a heterozygous mutation $(\mathrm{c} .146+1 \mathrm{G}>\mathrm{A})$ of the gene in the family pedigree. To date, only two cases of ACP have been reported in China and less than 60 families' cases worldwide $(9,10)$. To the best of our knowledge, the c.146+1G>A mutation in the $\mathrm{CP}$ gene has not been previously reported in China.

To date, approximately 28 missense, 17 frameshift, 13 splicing, and 8 nonsense mutations of CP in ACP have been described worldwide (11). The majority of cases are due to homozygous mutations (related to the family history of consanguinity), but compound heterozygosity has also been described (12). Most of these mutations lead to the formation of a stop cordon, and the produced protein does not have the necessary structures for enzymatic function in cellular iron transport (13). In the present case, a homozygous mutation in the $\mathrm{CP}$ gene $\mathrm{c} \cdot 146+1 \mathrm{G}>\mathrm{A}$ was identified, and a type of mutation has only been reported in a Caucasian case in Belgium (12). In addition, 14 members of this family were screened for genetic mutations, and blood biochemical parameters were measured. Among them, four family members (one of two elder sisters, one elder brother, and her parents) were found to have a heterozygous mutation in the CP gene $($ c. $146+1 \mathrm{G}>\mathrm{A})$, which might be due to the fact that the parents of the index case were second cousins. The homozygous mutations of 

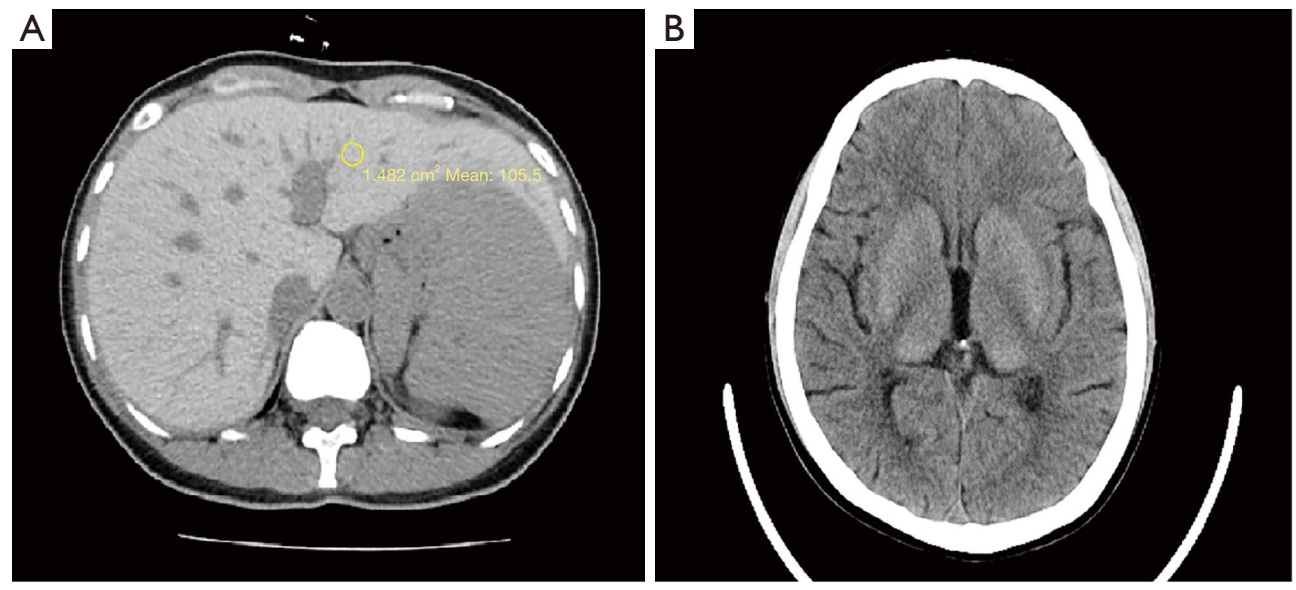

Figure 1 Brain and abdominal CT images. (A) The liver showed hepatic cysts with high density revealing the deposition of iron. (B) Brain CT showed high intensity areas in the bilateral thalami and basal ganglia. CT, computed tomography.

Table 2 Relative indexes of iron metabolism

\begin{tabular}{lcc}
\hline Parameter & Value & Normal value \\
\hline Fe $(\mu \mathrm{mol} / \mathrm{L})$ & 6 & $11.0-29.0$ \\
Ferritin $(\mathrm{ng} / \mathrm{mL})$ & $>2,000$ & $5-120$ \\
TIBC $(\mu \mathrm{mol} / \mathrm{L})$ & 43.3 & $45.00-82.00$ \\
TS $(\%)$ & 13.9 & $20.0-50.0$ \\
Ceruloplasmin $(\mathrm{g} / \mathrm{L})$ & $<0.0183$ & $0.2-0.6$ \\
Copper $(\mu \mathrm{mol} / \mathrm{L})$ & 3.3 & $12.0-15.0$ \\
\hline
\end{tabular}

Fe, serum iron; TIBC, total iron binding capacity; TS, transferrin saturation.

$\mathrm{CP}(\mathrm{c} .146+1 \mathrm{G}>\mathrm{A})$ in the present case resulted in a complete lack of $\mathrm{CP}$, a decrease in transferrin saturation, and an elevated SF level.

$\mathrm{CP}$ is an oxidase characterized as a copper $(\mathrm{Cu})$ containing protein that binds $40-70 \%$ of $\mathrm{Cu}$ in the plasma. There are two isoforms of this protein, a secretory form and a glycosylphosphatidylinositol (GPI)-linked form (2). Secretory CP plays a role as an antioxidant (14), while the GPI-linked form plays a key role in iron efflux from cells as a ferroxidase (15). It mediates the oxidation of ferrous iron $\left(\mathrm{Fe}^{2+}\right)$ to ferric iron $\left(\mathrm{Fe}^{3+}\right)$ and regulates the efficiency of iron efflux (16). The absence of CP impairs iron efflux from cells, resulting in marked iron accumulation in visceral organs such as the liver, pancreas, and central nervous system $(17,18)$. This mutation $(c \cdot 146+1 G>A)$ in the patient was localized at the 3' splice site of exon 1, an area with a highly conserved sequence, which might result in altered mRNA splicing and reduced transcript expression or lead to rapid mRNA degradation and abnormalities in CP synthesis. The absence of CP leads to pathological iron overload in the liver, pancreas, retina, and central nervous system. Subjects with CP suffer from DM, anemia, retinal degeneration, and neurological abnormalities, including neurological symptoms such as blepharospasm, orolingual, mandibular dystonia, chorea, dysarthria, ataxia, parkinsonism, and cognitive decline. From most reports published so far, it is estimated that $17 \%$ of cases would manifest neurological symptoms as the first sign, and $74 \%$ of cases would suffer from neurological sequelae over time (19). Given that the average age of onset of neurological manifestations of ACP is around 50 years, the present case also had no obvious neurodegenerative characteristic clinical symptoms and signs, except for mild memory decrease and blunt responses, even though iron was deposited in her basal ganglia and dentate nuclei on CT.

DM was the initial clinical feature of our case. In a systematic review of 55 ACP patients, $68.5 \%$ of patients had DM as the first sign at a median age of 38.5 and 39.5 (20). As mentioned in our report, the patient was diagnosed with DM. Although she had received all kinds of oral antidiabetic agents with well-controlled postprandial blood glucose levels, she still suffered from chronic fasting hyperglycemia and had to be administered with NPH insulin injection to reduce the fasting blood glucose levels. Iron overload is associated with an increased diabetes risk. The exact mechanisms underlying the association of ACP with diabetes in our ACP patients have not yet been completely elucidated. Features related to both 


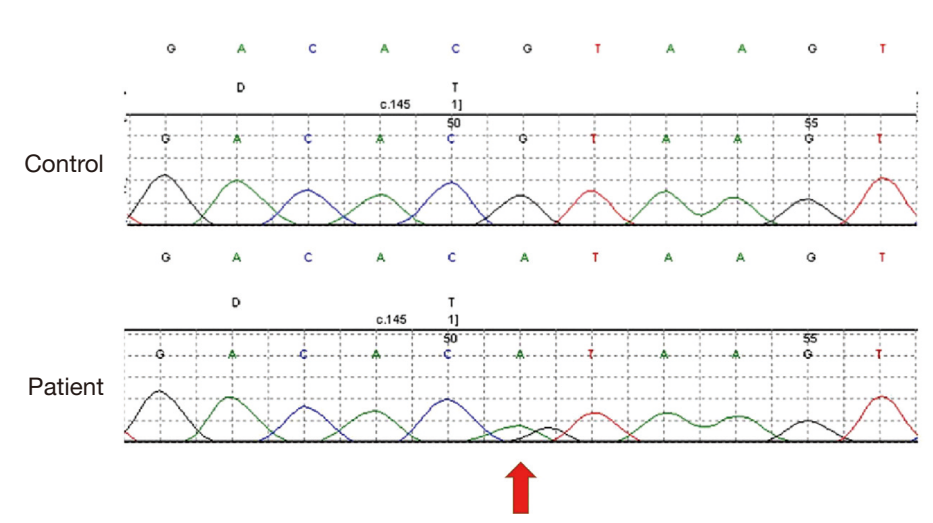

Figure 2 The results of a ceruloplasmin gene analysis. Direct sequencing of the ceruloplasmin gene revealed a homozygous ceruloplasmin gene mutation c. $146+1 \mathrm{G}>\mathrm{A}$ in the patient.

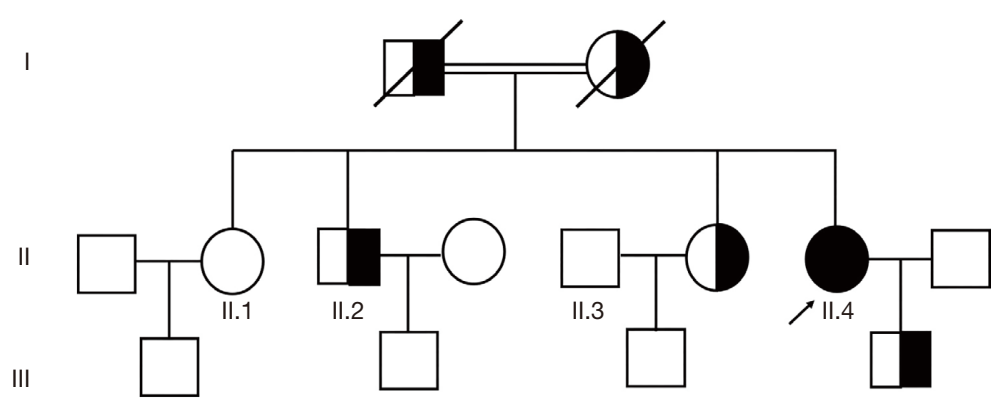

Figure 3 Pedigree of the affected family. Six members of the family are affected by the mutation of CP, the consanguineously married parents, the proband's 41-year-old brother, a 39-year-old sister, and a 2-year-old son were heterozygous carriers of c.146+1G>A. The index case is marked by an arrow. Squares denote men, circles denote women. Double lines indicate consanguineous marriages. Solid symbols denote individuals diagnosed with aceruloplasminemia marked by an arrow. CP, ceruloplasmin.

insulin resistance and beta cell dysfunction were present in the patients. First, a moderate iron overload in the liver with splenomegaly was observed on abdominal CT and ultrasound examinations. The liver plays an important role in glucose homeostasis. Deposition of iron in the liver has been reported to be linked to insulin resistance and hyperinsulinemia (21-23). Hepatic insulin resistance is the earliest and most common feature observed under iron overload conditions. Overloaded iron may impede insulin extraction in the liver and interfere with its suppressive effect on hepatic glucose production (24), which is the most important cause of fasting hyperglycemia. The higher level of HOMA-IR and lower level of QUICKI support elevated insulin resistance of the patient, in which the 75 th percentile value was used as the cutoff point to define insulin resistance, which corresponds to a HOMA-IR value of 2.31 as per the Shanghai Diabetes Studies background population study (25). In addition, deficiency of CP may lead to direct iron deposition in pancreatic $\beta$-cells as well. Accumulation of iron in $\beta$-cells enhances $\mathrm{Fe}^{2+}$ influx into the mitochondria, inhibits ATP synthesis, and eventually impairs insulin secretion (26). Moreover, iron is a strong pro-oxidant that serves as a catalyst in several cellular reactions that produce reactive oxygen species (27). There is evidence that excess iron results in $\beta$-cell oxidative stress and decreased insulin secretory capacity secondary to $\beta$-cell apoptosis and desensitization of glucose-induced secretion $(28,29)$. Consistently, the first and second insulin deposits were relatively low (based on the Shanghai Diabetes Studies background population study) in the present case (25).

Moreover, subjects with $C P$ gene mutations present with iron overload in the tissues, a phenotype that is difficult to distinguish from hereditary hemochromatosis $(\mathrm{HH})$. Both diseases share similar specific clinical features, including 
hyperglycemia secondary to pancreatic iron accumulation and increased hepatic iron stores $(30,31)$. In the present case, considering the consanguineous marriage in her parents, family history, and the finding of parenchymatous accumulation of iron in the liver led us to perform genetic screening focusing on hemochromatosis. $\mathrm{HH}$ is also an autosomal recessive disorder and the most common genetic iron overload disease (31). The most common forms of $\mathrm{HH}$ are inherited mutations in the HFE gene, characterized by elevated SF, serum iron, and transferrin-iron saturation levels in patients (32). However, an extremely high value of ferritin but low serum iron and transferrin saturation together with absent $\mathrm{CP}$ in serum were observed in the present case, which is not consistent with the laboratory features of HH. Furthermore, no mutations in HFE were found upon extended genetic examination for $\mathrm{HH}$.

In summary, we report a case of ACP diagnosed with diabetes with mild neurological symptoms. Although the diabetes of ACP is not included in the genetic etiology of $\mathrm{DM}$ as classified by the American Diabetes Association (33), hyperglycemia is one of the most common signs of ACP. Awareness of ACP should be considered in diabetic patients in routine clinical practice.

\section{Acknowledgments}

Funding: This work was funded by grants from the Shanghai Municipal Commission of Health and Family Planning Fund Project (20184Y0311 to YX) and Shanghai Sixth People's Hospital East Outstanding Young Fund Project (2019006 to YX).

\section{Footnote}

Reporting Checklist: The authors have completed the CARE reporting checklist. Available at https://apm.amegroups. com/article/view/10.21037/APM-21-1086/rc

Peer Review File: Available at https://apm.amegroups.com/ article/view/10.21037/APM-21-1086/prf

Conflicts of Interest: All authors have completed the ICMJE uniform disclosure form (available at https://apm. amegroups.com/article/view/10.21037/APM-21-1086/ coif). YX reports that this work was funded by grants from the Shanghai Municipal Commission of Health and Family Planning Fund Project (20184Y0311) and Shanghai Sixth People's Hospital East Outstanding Young Fund Project
(2019006). The other authors have no conflicts of interest to declare.

Ethical Statement: The authors are accountable for all aspects of the work in ensuring that questions related to the accuracy or integrity of any part of the work are appropriately investigated and resolved. All procedures performed in this study were in accordance with the ethical standards of the institutional and/or national research committee (s) and with the Helsinki Declaration (as revised in 2013). Written informed consent was obtained from the patient for publication of this case report and accompanying images. A copy of the written consent is available for review by the editorial office of this journal.

Open Access Statement: This is an Open Access article distributed in accordance with the Creative Commons Attribution-NonCommercial-NoDerivs 4.0 International License (CC BY-NC-ND 4.0), which permits the noncommercial replication and distribution of the article with the strict proviso that no changes or edits are made and the original work is properly cited (including links to both the formal publication through the relevant DOI and the license). See: https://creativecommons.org/licenses/by-nc-nd/4.0/.

\section{References}

1. Hellman NE, Gitlin JD. Ceruloplasmin metabolism and function. Annu Rev Nutr 2002;22:439-58.

2. Miyajima H. Aceruloplasminemia. Neuropathology 2015;35:83-90.

3. Fasano A, Colosimo C, Miyajima H, et al. Aceruloplasminemia: a novel mutation in a family with marked phenotypic variability. Mov Disord 2008;23:751-5.

4. Piperno A, Alessio M. Aceruloplasminemia: Waiting for an Efficient Therapy. Front Neurosci 2018;12:903.

5. Miyajima H, Nishimura Y, Mizoguchi K, et al. Familial apoceruloplasmin deficiency associated with blepharospasm and retinal degeneration. Neurology 1987;37:761-7.

6. Vroegindeweij LHP, Langendonk JG, Langeveld M, et al. New insights in the neurological phenotype of aceruloplasminemia in Caucasian patients. Parkinsonism Relat Disord 2017;36:33-40.

7. Parks NE, Vandorpe RA, Moeller JJ. Teaching NeuroImages: neurodegeneration with brain iron accumulation in aceruloplasminemia. Neurology 2013;81:e151-2.

8. Pelucchi S, Mariani R, Ravasi G, et al. Phenotypic 
heterogeneity in seven Italian cases of aceruloplasminemia. Parkinsonism Relat Disord 2018;51:36-42.

9. Shang HF, Jiang XF, Burgunder JM, et al. Novel mutation in the ceruloplasmin gene causing a cognitive and movement disorder with diabetes mellitus. Mov Disord 2006;21:2217-20.

10. Zhou L, Chen Y, Li Y, et al. Intracranial iron distribution and quantification in aceruloplasminemia: A case study. Magn Reson Imaging 2020;70:29-35.

11. Marchi G, Busti F, Lira Zidanes A, et al. Aceruloplasminemia: A Severe Neurodegenerative Disorder Deserving an Early Diagnosis. Front Neurosci 2019; $13: 325$.

12. Haemers I, Kono S, Goldman S, et al. Clinical, molecular, and PET study of a case of aceruloplasminaemia presenting with focal cranial dyskinesia. J Neurol Neurosurg Psychiatry 2004;75:334-7.

13. Kono S. Aceruloplasminemia: an update. Int Rev Neurobiol 2013;110:125-51.

14. Samokyszyn VM, Miller DM, Reif DW, et al. Inhibition of superoxide and ferritin-dependent lipid peroxidation by ceruloplasmin. J Biol Chem 1989;264:21-6.

15. Jeong SY, David S. Glycosylphosphatidylinositol-anchored ceruloplasmin is required for iron efflux from cells in the central nervous system. J Biol Chem 2003;278:27144-8.

16. Wang B, Wang XP. Does Ceruloplasmin Defend Against Neurodegenerative Diseases? Curr Neuropharmacol 2019;17:539-49.

17. Miyajima H, Takahashi Y, Kono S. Aceruloplasminemia, an inherited disorder of iron metabolism. Biometals 2003;16:205-13.

18. Kono S, Miyajima H. Molecular and pathological basis of aceruloplasminemia. Biol Res 2006;39:15-23.

19. Calder GL, Lee MH, Sachithanandan N, et al. Aceruloplasminaemia: a disorder of diabetes and neurodegeneration. Intern Med J 2017;47:115-8.

20. Vroegindeweij LH, van der Beek EH, Boon AJ, et al. Aceruloplasminemia presents as Type 1 diabetes in non-obese adults: a detailed case series. Diabet Med 2015;32:993-1000.

21. Chitturi S, George J. Interaction of iron, insulin resistance, and nonalcoholic steatohepatitis. Curr Gastroenterol Rep 2003;5:18-25.

22. Luque-Ramírez M, Alvarez-Blasco F, Botella-Carretero JI, et al. Increased body iron stores of obese women with polycystic ovary syndrome are a consequence of insulin resistance and hyperinsulinism and are not a result of reduced menstrual losses. Diabetes Care 2007;30:2309-13.

23. Rajpathak SN, Wylie-Rosett J, Gunter MJ, et al. Biomarkers of body iron stores and risk of developing type 2 diabetes. Diabetes Obes Metab 2009;11:472-9.

24. Ferrannini E. Insulin resistance, iron, and the liver. Lancet 2000;355:2181-2.

25. Zhao T, Lin Z, Zhu H, et al. Impact of body fat percentage change on future diabetes in subjects with normal glucose tolerance. IUBMB Life 2017;69:947-55.

26. Shu T, Lv Z, Xie Y, et al. Hepcidin as a key iron regulator mediates glucotoxicity-induced pancreatic $\beta$-cell dysfunction. Endocr Connect 2019;8:150-61.

27. Yauger YJ, Bermudez S, Moritz KE, et al. Iron accentuated reactive oxygen species release by NADPH oxidase in activated microglia contributes to oxidative stress in vitro. J Neuroinflammation 2019;16:41.

28. Hatunic M, Finucane FM, Brennan AM, et al. Effect of iron overload on glucose metabolism in patients with hereditary hemochromatosis. Metabolism 2010;59:380-4.

29. Cooksey RC, Jouihan HA, Ajioka RS, et al. Oxidative stress, beta-cell apoptosis, and decreased insulin secretory capacity in mouse models of hemochromatosis. Endocrinology 2004;145:5305-12.

30. Kawabata H. The mechanisms of systemic iron homeostasis and etiology, diagnosis, and treatment of hereditary hemochromatosis. Int J Hematol 2018;107:31-43.

31. Elsaid MI, John T, Li Y, et al. Health Care Utilization and Economic Burdens of Hemochromatosis in the United States: A Population-Based Claims Study. J Manag Care Spec Pharm 2019;25:1377-86.

32. Murphree CR, Nguyen NN, Raghunathan V, et al. Diagnosis and management of hereditary haemochromatosis. Vox Sang 2020;115:255-62.

33. Report of the Expert Committee on the Diagnosis and Classification of Diabetes Mellitus. Diabetes Care 1997;20:1183-97.

Cite this article as: Xiao $\mathrm{Y}$, Zhu C, Jiang F, Gao Q, Lu H, Wang C, Wei L. Novel ceruloplasmin gene mutation causing aceruloplasminemia with diabetes in a Chinese woman: a case report. Ann Palliat Med 2022;11(7):2516-2522. doi: 10.21037/apm21-1086 